Excluding stock from riverbanks for environmental restoration: the influence of social norms, drought, and off-farm income on landholder behaviour

Harriet E Moore*, Ian D Rutherfurd**, Murray C Peel***

*School of Geography, University of Lincoln, Lincolnshire

**School of Geography, The University of Melbourne, Victoria, Australia

***Infrastructure Engineering, The University of Melbourne, Victoria, Australia

HaMoore@lincoln.ac.uk 


\title{
1 Excluding stock from riverbanks for environmental restoration: the influence 2 of social norms, drought, and off-farm income on landholder behaviour

\begin{abstract}
Governments often use voluntary agreements to encourage landholders to adopt environmental practices, such as excluding stock from grazing riverbanks. In Victoria, Australia, government agencies subsidize the adoption of these projects, while landholders are required to continue maintaining stock exclusion indefinitely. In the absence of further financial or legal enforcement, landholder compliance depends on the motivation and decision-making of individual landholders. Social beliefs about the responsibility of landholders to improve the condition of degraded riverine ecosystems, known as social norms, influence farmers to adopt new environmental practices. The influence of social norms on behaviour weakens when people perceived themselves to be constrained. From late 1996 to mid-2010 landholders in Victoria endured more than ten years of drought that has reduced productivity, and income. Drought conditions may influence whether landholders continue to exclude stock over the long-term, despite holding positive social norms. However, behaviour is influenced by perceptions of constraint; landholder perceptions may not reflect drought severity. Perceived drought affectedness may also be related to the amount of income obtained from farm activities. This study examined the relationship between social factors, (including injunctive and descriptive social norms, and symbolic and instrumental social beliefs, perceived drought affectedness, actual drought severity), and the percentage of overall income that landholders obtain from farm activities. A social survey, and assessment of river restoration projects, was conducted with 93 landholders in rural Victoria, Australia. We found that landholders who continue to graze riverbanks hold weaker social norms about excluding stock in drought conditions. Grazing behaviour was explained by social norms, and perceived drought affectedness together. Perceived drought affectedness was best explained by actual drought severity, but also by the amount of income obtained from farming activities, rather than either factor alone. Policy makers should consider using drought relief funding to subsidize the purchase of additional stock feed during droughts to encourage farmers to continue environmental stock exclusion, particularly when farmers rely on farm activities for most of their income.
\end{abstract}

\section{Introduction}

Efforts to improve environmental management in river basins often involve projects with rural landholders One of the most common projects in Australia (Brooks \& Lake, 2007) and the United States of America (Kondolf et al., 2007) involves establishing voluntary agreements with landholders to exclude stock from grazing riverbanks in order to promote ecological recovery. In Victoria, Australia, government agencies subsidize the cost of adopting environmental behaviours for stock exclusion, such as constructing riverbank fencing, while landholders are legally responsible for continuing to exclude stock from the fenced riverbank (Department of 
Sustainability and Environment, 2011). To be successful, stock exclusion behaviours must be maintained indefinitely (Moore \& Rutherfurd, 2017). Ideally, compliance should be monitored and enforced (Gunningham, 2003). However, in practice, stock exclusion projects are rarely assessed, and, to our knowledge, non-compliance has never been penalized. In the absence of legal repercussions, the long-term success of these projects depends on the motivation of individual landholders.

An underlying assumption of using voluntary agreements is that landholders are motivated by non-monetary incentives (Danne, 2003), such as beliefs about social pressure to behave or not behave in a certain way, known as social norms (Armitage \& Conner, 2001). Numerous studies suggest that environmental social norms influence landholders to adopt environmental behaviours, including stock exclusion (e.g., Greiner \& Gregg, 2011; Wauters et al., 2010). However, no research has explored whether environmental social norms also motivate landholders to continue to maintain environmental projects (in this case, stock exclusion) over the long-term.

Stock exclusion involves different activities and costs for adoption and maintenance. Thus, landholders may be influenced by different motivations and barriers to adopt a project, as compared to maintaining a project (Moore \& Boldero, 2017). Establishing stock exclusion is subsidized, however, maintenance involves costs associated with growing or purchasing additional feed for stock to compensate for lost fodder after the exclusion of stock from grazing riverbanks. Riverbanks can produce up to $25 \%$ more fodder for stock than pastures (Aarons et al., 2013). Furthermore, the cost of maintaining stock exclusion is exacerbated during droughts. Reduced pasture growth, and, thus farm incomes, simultaneously increases the need to purchase stock feed, and reduces the financial capacity to do so. Perceived constraints, such as cost or financial loss, can reduce the influence of social norms on behaviour (Ajzen, 1991). Between 1997 and 2010 (Steffen, 2015) landholders in Victoria experienced one of the most persistent and severe droughts in the period of European occupation (known as the Millennium Drought), resulting in reduced agricultural production and increased debt (Horridge et al., 2005; Mpelasoka et al., 2008). Thus, while environmental social norms may motivate landholders to adopt stock exclusion behaviour, the costs associated with purchasing stock feed, particularly in the context of the Millennium Drought and continuing financial hardship, may reduce the influence of social norms on the maintenance of stock exclusion.

This study investigated the relationship between the continued maintenance of stock exclusion behaviour, environmental social norms, and drought, in three regions of Victoria, Australia. The purpose of the research was two-fold. First, we explored whether social norms influence the maintenance of stock exclusion, and therefore the effectiveness of using voluntary agreements for river restoration projects that involve landholders. Second, we examined the relationship between drought and landholder behaviour.

Social rural research about the relationship between agricultural environmental behaviour and social beliefs often uses very broad measures of social beliefs (e.g.,Greiner \& Gregg, 2011), rather than measures of specific cognitive constructs, such as different types of social norms (Burton, 2004). Behavioural research makes several distinctions between types of social norms 
that have important implications for the design of interventions to promote environmental behaviour in rural communities. For example, Cialdini et al. (1990) distinguish between social norms about how an individual believes they 'ought' to behave, known as injunctive norms, and social norms about how an individual believes significant others 'actually' behave, known as descriptive norms. This distinction is important because each type of norm has distinctly different conceptual and motivational foundations (Cialdini, 2007). Injunctive norms are "concerned with perceived social pressure, that is, the person's potential to gain approval or suffer sanctions from significant others for engaging in a behaviour” (Rivis \& Sheeran, 2003, p. 219). Descriptive norms are beliefs about the prevalence of behaviour and, thus, are influenced by information about how important others actually behave (Lapinski \& Rimal, 2005). Interventions can promote either descriptive or injunctive norms to encourage proenvironmental beahviour (Biel \& Thøgersen, 2007; Cialdini, 2007; Göckeritz et al., 2010). With one exception (Minato, Curtis, \& Allan, 2010), rural research does not distinguish between injunctive and descriptive norms (e.g., Fielding et al., 2008). Minato et al. (2010) analysed landholder responses to open-ended survey questions and identified injunctive and descriptive social norms, rather than using direct measures of these constructs. Thus, we examine the relationship between stock exclusion and both injunctive and descriptive social norms.

Further, people can simultaneously hold multiple, often conflicting, social beliefs about a single action or object. A common distinction is made between symbolic and instrumental beliefs (e.g., Cary, 1993; Crandle et al., 1997; Lievens, 2007). Symbolic beliefs reflect long-standing ideology, and tend to be unaffected by self-interest, while instrumental beliefs are, "founded on the real-world consequences of actions.” (Crandle et al., 1997, p.96). Thus, social norms may vary depending on the context of the belief object or activity, and whether the context pertains to ideology or self-interest. For example, instrumental beliefs about contagion have more influence on the activity, 'keeping social distance from persons with HIV/AIDS', than symbolic beliefs about the association of HIV/AIDS with drug use and homosexuality (Crandle et al., 1997). Thus, an individual could hold positive injunctive norms towards homosexuality, and yet choose to keep social distance from persons with HIV/AIDS on the basis of negative beliefs about contagion.

Similarly, Cary (1993) found that landholders can simultaneously hold two types of beliefs about how they 'ought' to behave in relation to environmental projects. Positive beliefs about the importance of environmental behaviour tend to be symbolic in nature; symbolic beliefs may contribute meaningfully to social ideology but do not necessarily result in the performance of environmental behaviour. Rather, the performance of environmental behaviour is influenced to a greater degree by beliefs about the practical value of the behaviour, such as the impact that performing the behaviour will have on farm businesses. These instrumental beliefs may conflict with symbolic beliefs held about the same behaviour (e.g., Crandall et al., 1997). For example, landholders may believe that ideally they 'ought' to maintain stock exclusion, while simultaneously believing that in reality they 'ought not' to maintain stock exclusion if there are negative repercussion for their farm business. Thus, the strength of injunctive social norms may vary depending on the context of the activity, in this instance, whether performing environmental behaviour has a negative impact on farm businesses. 
The fact that people can hold multiple conflicting beliefs about a single behaviour suggests that specifying the context of an activity or object is important for accurately measuring social norms. Thus, we examined the relationship between landholder environmental behaviour, and two different types of injunctive social norms: injunctive social norms about symbolic beliefs, and injunctive social norms about instrumental beliefs. We chose to distinguish between symbolic and injunctive beliefs by constructing social norm measures that stipulate two conflicting scenarios: (1) ideal scenarios that present no negative repercussions for farm businesses; and (2) less than ideal scenarios that present negative repercussions for farm businesses. The scenarios were related to the presence or absence of drought conditions. Following Cary (1993), we anticipated that injunctive norms about maintaining stock exclusion in scenarios of good water availability and high farm productivity would be symbolic in nature, and thus not related to whether landholders maintain stock exclusion. In contrast, we expected that injunctive norms about maintaining stock exclusion in scenarios of drought and low farm productivity would be instrumental in nature, and thus related to whether landholders maintain stock exclusion.

The second purpose of this study is to explore the relationship between drought and the maintenance of stock exclusion projects. Drought conditions can prevent landholders from adopting environmental practices (Curtis et al., 2008). Ajzen (1991) argued that perceived behavioural control (PBC) lessen the influence of social norms on the performance of behaviour. We did not measure PBC, however, in principle Ajzen (1991) suggests that perceptions of constraint can weaken the influence of social norms on behaivour. Importantly, landholder perceptions about the impact of drought on their farm businesses do not necessarily reflect the actual climatic severity of drought conditions. For example, Lukasiewicz et al (2012) found that landholder beliefs about climate change are based on local experiences rather than a scientific understanding of climatic conditions. Along with actual climatic conditions, perceptions of drought affectedness may also be influenced by how heavily landholders rely on farm businesses for their financial security. Nelson et al. (2005) found that landholders who have multiple sources of income tend to be more resilient to external stressors, such as climatic events, compared to those with only a single source of income. Similarly, Kebede (1992) found that landholders with incomes from both agricultural activities and off-farm activities were more likely to adopt environmental behaviour. Riparian areas produce significantly greater amounts of fodder than pastures, and preventing cattle from grazing can result in financial losses, both in terms of the additional cost of purchasing extra fodder, and in terms of needing to allocate additional pasture to fodder, that would otherwise be used for commercial production (Aarons et al., 2013). In times of drought and low farm productivity, landholders who obtain a higher percentage of their overall income from off-farm employment may be more capable of purchasing feed, and, as a result, more likely to maintain stock exclusion from the river frontage. Therefore, drought severity and the amount of income obtained from farm activities may influence perceptions of drought affectedness, and in turn whether landholders maintain stock exclusion.

Drought relief funding for stock management is available for landholders on the basis of drought severity; the Victorian Government uses climate data obtained from the Bureau of Meteorology to make decisions about the eligibility of landholders for financial aid (Victoria 
State Government, 2017). Drought relief packages could be used to encourage landholders to continue stock exclusion during drought events. However, the effectiveness of this approach depends on whether landholders' perceptions reflect actual drought severity. Thus, our study examined the relationship between drought perception and the maintenance of stock exclusion behaviour, and the relationship between perceived drought affectedness, actual drought severity, and the amount of overall income that landholders obtain from farm activities.

This research was conducted with landholders from three regional authorities in Victoria, known as Catchment Management Authorities (CMAs). The study makes three contributions to rural studies, research about environmental behaviour, and environmental policy in agricultural communities. Firstly, rural research about environmental behaviour often examines broad social factors rather than specific cognitive constructs (Burton, 2004). However, understanding the precise nature of social beliefs is important for designing effective interventions (Cialdini, 2003, 2007). Thus, we distinguish between injunctive social norms about how landholders believe they 'ought' to behave, and descriptive social norms about how landholders perceive others 'actually' behave. Secondly, farmers may hold multiple, conflicting beliefs about performing environmental behaviour (Cary, 1993). Thus, we also distinguish between two types of injunctive social norms: symbolic social norms about how landholders believe they should behave in ideal scenarios, and instrumental social norms about how landholders believe they should behave in less than ideal scenarios that have negative repercussions for farm businesses. The third contribution of this research is about the relationship between perceived drought affectedness, actual drought severity and the amount of income that landholders obtain from farm activities.

\section{Hypotheses and research questions}

\subsection{Injunctive norms}

Cary (1993) suggested that while landholders can hold conflicting symbolic and instrumental beliefs about an issue or activity, their behaviour is more consistent with their instrumental beliefs about the practical value of performing an activity. We assessed two types of injunctive norms; social norms about symbolic beliefs, and social norms about instrumental beliefs. Specifically, we assessed injunctive social norms reflecting symbolic beliefs that landholders should exclude stock from riverbanks in scenarios of good water availability and high farm productivity. We also assessed injunctive social norms reflecting instrumental beliefs that landholders should exclude stock from riverbanks in scenarios of drought and low farm productivity. We expected that there would be no relationship between symbolic norms and stock grazing, and, thus, that there would be no difference between landholders that graze and landholders who do not graze for norms about excluding stock in years of good water availability (H1) and years of high farm productivity (H2).

Research suggests that drought, resulting in low farm productivity, and financial insecurity, are barriers to the adoption of environmental behaviour in agricultural communities (e.g., Curtis et al., 2008). Thus, we expected that landholders who continue to graze the riverbank would report weaker instrumental norms about excluding stock in years of drought 
212 (H3) and in years of low farm productivity (H4), compared to landholders who do not graze. In

213 addition, both social norms and perceptions of barriers, such as financial insecurity, can

214 influence behaviour (Ajzen, 1991). Thus, we expected that the injunctive social norm about

215 excluding stock in drought conditions, and perceived drought affectedness would explain greater

216 variance in whether or not landholders continue to graze the riverbank than the social norm alone

217 (H5).

218

219

220

221

222

223

224

225

226

227

228

229

230

231

232

233

234

235

236

237

238

239

240

241

242

243

244

\subsection{Drought affectedness, drought severity, and income}

Drought conditions negatively impact farm businesses (Mpelasoka et al., 2008). We anticipated that landholders who graze the riverbank would report higher drought affectedness than those who exclude stock from the riverbank (H6). Furthermore, perceived drought affectedness may be influenced by actual climatic conditions, as well as the degree that landholders rely on agricultural activities for income. Accordingly, we predicted that there would be a positive relationship between actual drought severity and perceived drought affectedness (H7), and the percentage of overall income obtained from farm activities and perceived drought affectedness (H8). We also examined the relationship between perceived drought affectedness and drought severity at the regional scale. A preliminary examination of climate data indicated that during the Millennium Drought, landholders in CMA C experienced greater drought severity compared to landholders in CMA A and CMA B. Thus, we expected that landholders in CMA C would report higher drought affectedness than those in CMA A and CMA B (H9). We also expected that, together, drought severity and the percentage of overall income obtained from farm activities, would predict greater variance in perceived drought affectedness than either variable individually (H10).

\subsection{Descriptive social norms}

In addition to the above hypotheses, we anticipated that landholders would report that 'others like them' behave in a similar way to themselves (Goldstein et al., 2008). For example, we expected that landholders who report they graze frequently, would also report that 'others like them’ graze frequently.

245

246

Table 1 about here-

\section{Methods}

\subsection{Research design and sampling}

The current research involved three methods of data collection. Firstly, data about evidence of stock exclusion or continued grazing on riverbanks was collected CMA staff during monitoring and assessment projects conducted between 2013 and 2014 in three regions of Victoria referred to here as CMA A, CMA B, and CMA C. In total 231 assessments were conducted at landholder properties in CAM A $(N=137)$, CMA B $(N=50)$, and CMA C $(N=44)$. These landholders were involved in projects funded by CMAs to fence riverbanks to exclude stock from gazing the 
riparian area. The assessment projects were funded by the Victorian State Government. Secondly, data about social norms, perceived drought affectedness, and the amount of income landholders obtain from farm activities were collected using a social survey that was distributed by mail to the 231 landholders involved in CMA assessments. In total, 93 landholders (40\% return rate) completed and returned usable surveys. A small number of landholders completed the survey by phone due to mail delays in regional Victoria. Finally, data about drought severity was obtained from the Bureau of Meteorology. This research was approved by a Behavioural Sciences Human Research Ethics board.

\subsection{Measures of behaviour, social norms, drought, and income}

Stock exclusion behaviour was measured by CMA staff during visual inspections of landholder properties. Evidence of continued stock grazing on the riverbank included hoof marks, eaten vegetation, and the presence of cows. Evidence of grazing was coded as ' 1 '. An absence of evidence of grazing, meaning total exclusion, was coded as ' 2 '.

Injunctive social norms about stock exclusion were assessed with four 7-point Likert scale items that were included on the social survey. Our study is the first to develop social norm measures for stock exclusion behaviour. Draft social surveys were reviewed by ten landholders and six CMA staff. During interviews these participants suggested that other landholders may be unlikely to respond to injunctive norm survey items structured in the traditional format (Ajzen, 2017), which is: 'how do others think you should behave'. It was proposed that farmers might respond negatively, or choose not to respond, to direct statements that suggest other people's expectations should influence their behaviour. This is consistent with the results of a survey of 794 landholders in Victoria conducted by Curtis et al. (2008). Their survey included two personal norm items and one injunctive social norm item. While most landholders who completed their survey responded to the personal norm items, 52\% of participants either did not respond to the injunctive norm item or responded 'N/A'. Following discussions with the landholders who reviewed our draft survey, we developed an alternative measure of injunctive norms. Our item structure was 'landholders should' rather than 'other people think landholders should'. Thus, while non-conventional, our items do capture beliefs about how landholders think they 'ought' to behave, which is the foundation of injunctive social norms (Cialdini et al., 1990).

The injunctive social norm survey items, summarized in Table 2, were also designed to reduce the likelihood of a common respondent bias associated with social research (e.g., Choi \& Pak, 2005), including environmental behaviour (e.g., Hirsch, 2010), referred to as 'acquiescence bias'. Acquiescence bias is the tendency of survey respondents to agree with most statements (Van Sonderen et al., 2013). This phenomenon is often attributed to the perceived social desirability of agreeing with statements on questionnaires rather than disagreeing with statements (Choi \& Pak, 2005), and perceptions of the researcher's expectations about how study participants should respond to survey items (Fuji et al., 1985). The participants who reviewed the draft survey suggested that most landholders are familiar with the expectations of CMA staff, and thus, would agree with statements about excluding stock from grazing in ideal scenarios related to good water availability and high farm productivity. By comparison, there is an understanding that drought events warrant deviation from ordinary farming practices (e.g., Curtis et al., 2008). Thus, it was anticipated that landholders were more likely to respond honestly to 
statements about less than ideal scenarios related to drought and low farm productivity, compared to statements about ideal scenarios. Therefore, the symbolic social norm survey items were revised to reduce the likelihood of acquiescence bias.

One common approach to counter acquiescence bias is to reverse the wording of questionnaire items to change the direction of the statement from positive to negative (e.g., Qasem \& Gul, 2014; Solís Salazar, 2015). For example, prior to revising the survey in response to landholder and CMA feedback, the symbolic social norm survey items were structured in a positive direction: 'Landholders should be prepared to exclude stock from the fenced frontage in years of good water availability'. Landholders may perceive that the leading term 'should' reflects the beliefs of CMA staff; that landholders should exclude stock in ideal conditions. Thus, one option to overcome acquiescence bias was to structure symbolic social norm survey items negatively, as follows: 'Landholders should not be prepared to exclude stock from the fenced frontage in years of good water availability. However, using negatively structured items is controversial, and is widely considered to be ineffective (e.g., Qasem \& Gul, 2014). For example, Van Sonderen et al. (2013) argue that negatively structured survey items can confuse respondents and result in contaminated data. Thus, rather than reversing the wording of symbolic norm survey items, we chose to reverse the implications of agreeing with statements to prompt respondents to pay closer attention (Solís Salazar, 2015).

The revised symbolic norm survey items were structured to encourage landholders with strong symbolic social norms to disagree, rather than agree with the survey items. The items were structured as follows: 'Landholders should be prepared to exclude stock from the fenced frontage only in years of good water availability'. Disagreement with the statement, rather than agreement, implies the symbolic belief that landholders should exclude stock from the fenced frontage in all scenarios, rather than only in favorable scenarios. Thus, it was expected that landholders who hold strong symbolic beliefs would disagree with the symbolic social norm survey items, while landholders who hold weak symbolic beliefs would agree with the survey items.

-Table 2 about here-

Participants indicated the extent to which they agreed with each item using a 1 ("strongly disagree” to 7 (“strongly agree”) response scale, where 4 indicates "neither agree nor disagree”. Two items assessed the symbolic beliefs that landholders should be prepared to exclude stock from grazing the riverbank in years of good water availability, and in years of high farm productivity. Two items assessed the instrumental beliefs that landholders should exclude stock from gazing the riverbank in years of drought, and in years of low farm productivity.

Descriptive social norms were assessed by comparing how an individual behaves with their beliefs about how other people behave (Cialdini, 2007). Descriptive norm survey items were also altered following feedback. All of the ten landholders who reviewed our draft survey indicated that farmers would not be able to answer questions about 'how other farmers in your area behave' because of the regional variability of farming enterprise. Therefore, the items were revised to ask about 'how other farmers like you behave (e.g., if you are a cattle grazer, other cattle grazers in your region)'. Our social survey included items asking landholders to self-report 
about their own grazing behaviour, and items asking landholders to estimate how other landholders 'like them' behave. Items included asking landholders to describe the duration, regularity, and seasonality of their own grazing regimes and of other landholders' grazing regimes. We intended to examine whether landholders' descriptive norms reflected their own behaviour.

Drought affectedness and the amount of income obtained from farm activities were assessed using one 7-point Likert scale survey item and two open-ended survey items. The Likert scale item assessed participants' perception of their drought affectedness in terms of the impact of drought on their farm business. Participants indicated the extent of their perceived drought affectedness using a 1 (“not at all affected”) to 7 (“extremely affected”) response scale. Two open-ended items asked participants to report the percentage of overall income obtained from farming activities, and to list the main ways that drought affected their farm business.

Drought severity was determined using gridded daily precipitation data from the Bureau of Meteorology's Australian Water Availability Project (AWAP) dataset (Jones, Wang, \& Fawcett, 2009). For each farm property, daily precipitation was extracted from an AWAP grid cell $\left(0.05^{\circ} \times 0.05^{\circ}\right.$, approximately $\left.5 \mathrm{~km} \times 5 \mathrm{~km}\right)$ representative of the farm's latitude and longitude for the period 1900-2016. The daily values were summed to calendar year values. Drought severity was computed by dividing the average precipitation value for the drought years (19972010) by the average value for the entire period on record (1900-2016), to produce a ratio representing drought severity for each farm property. The coefficient of variance for the years 1900-2016 was also calculated for each site. The drought severity ratio indicates the extent that the average precipitation during the Millennium Drought deviated from the average precipitation of the year 1990-2016 for each landholder property. Drought severity ratio values range from 0 to 1; high values indicate no deviation and low values indicate high deviation. A high drought severity ratio, such as 0.9 , might suggest an area has experienced only minimal reduced precipitation during the drought. However, a low coefficient of variability, such as 0.1 , indicates that even a slight deviation from the average precipitation is likely to be climatically significant.

\subsection{Data analysis}

Our research involved both qualitative and quantitative data. Therefore multiple methods of data analysis were used, including statistical analysis and thematic content analysis.

Statistical analysis. Hypotheses 1 to 4 about the relationship between injunctive norms and stock grazing were examined using t-tests. Hypothesis 5 about the amount of variance of grazing behaviour explained by the social norm for excluding stock in drought conditions, and perceived drought affectedness, was examined by computing a stepwise multiple regression.

Hypothesis 6 about the relationship between perceived drought affectedness and stock grazing was examined using a t-test. Hypotheses 7 about the relationship between perceived drought affectedness and actual drought severity was addressed by computing a Pearson's correlation coefficient. Hypothesis 8 about the relationship between perceived drought affectedness and the amount of income landholders obtain from farm activities was also addressed by computing a Pearson's correlation coefficient. Hypothesis 9 about differences of 
perceived drought affectedness between CMA A, CMA B, and CMA C was addressed by computing a one-way ANOVA. Finally, a stepwise multiple regression was used to examine Hypothesis 10 about the amount of variance of perceived drought affectedness explained by drought severity and income together.

Thematic analysis of open-ended survey responses. Responses to open-ended survey items about descriptive norms and the ways that drought as impacted farm businesses were thematically analysed and coded. Common themes were determined by identifying objects and categories in respondent data (H. Jansen, 2010), and recording the frequency of mentions (Castro, Kellison, Boyd, \& Kopak, 2010).

\section{Results}

\subsection{Descriptive results}

Stock exclusion. CMA data about evidence of grazing indicated that of the 93 landholders who completed the social survey, 53 (57\%) grazed in the fenced frontage, whereas 40 (43\%) did not.

Injunctive norms. Table 3 displays the means, standard deviations, and correlations for landholder responses to injunctive norm survey items. There was a strong positive correlation between the symbolic beliefs about excluding stock from grazing in the ideal scenario of good water availability and beliefs about excluding stock in the ideal scenario of high farm productivity. There was also a strong positive correlation between the instrumental beliefs about the responsibility of landholders to exclude stock in times of drought, and the instrumental beliefs about excluding stock in times of low farm productivity. There was no relationship between symbolic beliefs and instrumental beliefs.

Table 3 about here-

Descriptive social norms. It was anticipated that landholders would estimate what 'other people like them' do in relation to stock grazing, and that these estimations would reflect their own behaviour (Goldstein et al., 2008). However, 65\% of responses to the descriptive norm items were 'NA' or 'I don't know'. Only 15\% of responses estimated what other landholders do and, of these, only $7 \%$ gave responses that were consistent with their own behaviour.

Responses also included more than 100 comments that suggest the participants do not hold strong descriptive norms about grazing behaviour. Three themes emerged from the thematic analysis of these comments. Firstly, 24\% of comments indicated that stock exclusion is not normative behaviour, rather landholders perceive their involvement in exclusion projects as the behaviour of a minority. For example, comments included "Most don't fence the river", and "the neighbours think we're mad for fencing off grazing land”.

Secondly, 33\% of comments indicated that landholders are unable to estimate others' behaviour because they lack the appropriate knowledge, and that lack of knowledge is at least in 
part related to the geographical isolation of stock farmers, from others 'like them'. Comments included "I don't know what other farmers do, silly question!", and "no other dairy farmers in our area”. Thirdly, 43\% of comments indicated that others' behaviour is highly contextual, and thus cannot be estimated. For example, in response to an item about the percentage of other landholders that graze the fenced frontage, one participant commented that "Some would, some wouldn't, everyone is different".

Perceived drought affectedness and farm income. Table 4 displays the means and standard deviations for landholder responses to survey items about drought affectedness and farm income. Farm businesses are moderately affected by drought conditions. On average, farmers obtain $50 \%$ of income from farm activities, although the standard deviation indicates considerable variability.

Table 4 about here-

Table 5 demonstrates that there was no difference for percentage income from on-farm activities between landholders in CMA A $(M=58.85, S D=40.59)$, CMA B $(M=53.43, S D=42.63)$, and CMA C $(M=38.20, S D=39.67)$, F $(2,84)=1.91, p=.15$.

Table 5 about here-

Responses to the open-ended survey item about the ways that drought has impacted farm businesses were analysed and coded. In total, 81 landholders responded to the open-ended survey item about the ways that drought has impacted their farm businesses. Common themes included the psychological impact of drought on farming communities, the ecological impact of drought on riverbank vegetation, and the impact of drought on water availability, stock management, and financial security.

The most common impacts were related to financial security $(N=42)$, such as reduced income and increasing debt, and stock management $(N=39)$, such as shortage of fodder and being forced to destock. Two landholders reported spending between \$200, 000 and \$500, 000 on additional feed. One landholder reported depleting his retirement funds to subsidize the cost of additional feed. Further, landholders who continue to graze mentioned these themes more frequently than landholders who exclude stock from grazing. The impact of drought on financial security was mentioned by $50 \%$ of landholders who continue to graze, and $40 \%$ of landholders who exclude stock from grazing. The impact of drought on stock management was also mentioned by $50 \%$ of landholders who continue to graze, and $35 \%$ of landholders who exclude stock.

Drought severity. On average, the drought severity ratio for the study sites was high $(M=$ $.86, S D=.02)$, however, the coefficient of variance was low $(M=.26, S D=.04)$. Thus, the ratio indicates a significant deviation of rainfall from the average. ANOVA analysis revealed that there was a significant difference for both drought severity, and variance between the three regions. CMA C $(M=.84, S D=.02)$ experienced higher drought severity than CMA A $(M=.99$, 
$S D=.01)$ and CMA B $(M=.86, S D=.02)$. CMA C $(M=.23, S D=.04)$ also experienced higher variance of rainfall than CMA A $(M=.29, S D=.02)$ and CMA B $(M=.25, S D=.02)$. Table 5 presents the ANOVA analysis for difference of drought severity ratio and coefficient of variance between the three CMAs.

\subsection{Relationships between injunctive norms, stock grazing, and drought affectedness}

The t-test results for hypotheses 1 to 4 are reported in Table 6. Overall, our predictions about the distinction between symbolic and instrumental social norms were supported. Hypothesis 1 was supported as there was no difference between landholders who graze and those who do not graze, for the symbolic social norm about excluding stock from grazing in the scenario of good water availability. Hypothesis 2 was also supported, as there was no difference between landholders who graze, and landholders who exclude stock from grazing, for the symbolic social norm about excluding stock from grazing in the scenario of high farm productivity.

Hypothesis 3 was supported as landholders who graze reported weaker instrumental norms about excluding stock from grazing in drought conditions than landholders who exclude stock. Hypothesis 4 was also supported as landholders who graze reported weaker instrumental social norms about excluding stock from grazing in the scenario of low farm productivity, compared to landholders who exclude stock.

-Table 6 about here-

A stepwise multiple regression analysis revealed that together the instrumental injunctive norm about drought conditions and perceived drought affectedness accounted for $15.2 \%$ of the variance in grazing behaviour $(p=.001)$. The $\mathrm{R}^{2}$ change value and F-statistic were calculated to determine whether the addition of drought affectedness (Model 2 in Table 7 below) significantly improved the prediction of grazing behavior, compared to the injunctive norm independently (Model 1 in Table 7 below). Hypothesis 5 was supported as the addition of drought affectedness significantly improved prediction $\left(\mathrm{R}^{2}\right.$ change $\left.=.05, \mathrm{~F}=5.00, p=.03\right)$. The standardized coefficient (B), standardized error (SE), and unstandardized coefficient $(\beta)$ of the regression analysis are presented in Table 7.

Table 7 about here-

\subsection{Relationships between drought affectedness, drought severity, income, and stock grazing}

The results of the t-test computed to examine hypothesis 6 are reported in Table 6. Hypothesis 6 was supported, as landholders who graze reported higher perceived drought affectedness than landholders who exclude stock. Hypothesis 7 was partially supported as there was a weak positive relationship between landholder perceptions of drought affectedness and actual drought severity, $\mathrm{r}(82)=.50, \mathrm{p}<.00$. Hypothesis 8 was supported as there was a weak positive correlation between landholder perceptions of drought affectedness and the percentage of overall income 
that landholders obtain from farming activities, $\mathrm{r}(85)=.45, \mathrm{p}<.01$. In contrast to our expectations, landholders from CMA A $(M=6.07, S D=1.53)$ reported higher perceived drought affectedness than landholders from CMA B $(M=5.55, S D=1.50)$ and CMA C $(M=3.81, S D=$ 2.34), $\mathrm{F}(2,87)=12.61, p=.00$. However, there was no difference between CMA A and CMA $\mathrm{B} ; \mathrm{t}(57)=1.30, \mathrm{p}=0.20$. Thus, Hypothesis 9 was not supported; despite the fact that the region of CMA C experienced the greatest drought severity between the drought years of 1994 to 2010, landholders in CMA A and CMA B reported higher drought affectedness than landholders in CMA C.

Finally, while the percentage of income from farm activities and drought severity were weakly correlated with perceptions of drought affectedness, together these variables explained a significantly greater amount of variance, compared to either independently. A stepwise multiple regression analysis revealed that income and drought severity accounted for $30 \%$ of the variance in perceived drought affectedness $(p=.00)$. Independently, income accounted for only $20 \%$ of variance $(p=.00)$, while drought severity only accounted for $15 \%$ of variance $(p=.00)$. The $\mathrm{R}^{2}$ change value and F-statistic were calculated to determine whether the addition of drought severity (Model 2 in Table 8 below) significantly improved the prediction of perceptions, compared to percentage of income obtained from farm activities, independently (Model 1 in Table 8 below). Hypothesis 10 was supported as the addition of drought severity significantly improved prediction $\left(\mathrm{R}^{2}\right.$ change $\left.=.06, \mathrm{~F}=6.31, p=.01\right)$. The standardized coefficient $(\mathrm{B})$, standardized error (SE), and unstandardized coefficient $(\beta)$ of the regression analysis are presented in Table 8.

-Table 8 about here-

Figure 1 presents a schematic of the results of the stepwise multiple regression computed to test Hypothesis 5 about factors that explain whether or not landholders graze, and the results of the stepwise multiple regression computed to test Hypothesis about the factors that explain perceived drought affectedness. Together, the instrumental injunctive social norm about drought conditions and perceived drought affectedness, explain a statistically significantly greater variance of grazing behaviour than either factor alone. Likewise, together, the percentage of income obtained from farm activities and drought severity, explain a statistically significantly greater amount of variance of perceived drought affectedness than either factor alone.

\section{Discussion}

-Figure 1 about here- 
An underlying assumption of using voluntary agreements to implement environmental projects in rural communities, such as stock exclusion, is that landholders are motivated by non-monetary incentives, including social norms (Danne, 2003). The results of this study suggest that whether or not landholders maintain environmental behaviour is related to both instrumental social norms about the responsibility of landholders to exclude stock from grazing the riverbank in drought conditions, and perceived drought affectedness. Drought reduces farm productivity and increases the amount of stock feed that landholders must purchase. Landholders who perceive themselves to be more drought affected are more likely to graze stock on the fenced riverbank. Further, landholders with a higher proportion of overall income from farm activities perceive themselves to be more drought affected, and are more likely to graze cattle on the riverbank. Finally, responses to descriptive norm survey items suggest that landholders believe that participating in stock exclusion projects sets them apart from most other landholders, rather than reinforce their social identity.

\subsection{Symbolic and instrumental injunctive social norms, drought and stock exclusion}

Our findings are consistent with Cary (1993) who found that although farmers hold both symbolic and instrumental social beliefs, their behaviour reflects the pragmatic value of environmental management for their businesses. Landholders' behaviour is related to their instrumental injunctive social norms about the responsibility of farmers to exclude stock from grazing during times of drought and low farm productivity. As anticipated, there was no relationship between behaviour and symbolic social norms about grazing in ideal conditions of good water availability and high farm productivity. In contrast, there was a relationship between behaviour and instrumental social norms; landholders who continue to graze also hold weaker instrumental social norms than landholders who exclude stock entirely.

Further, landholders who graze report higher perceived drought affectedness than landholders who do not graze. Landholders who graze also reported that drought conditions resulted in reduced pasture for stock fodder and high costs associated with purchasing additional feed more frequently than landholders who exclude stock entirely, although the difference was not statistically significant. Importantly, landholders who graze reported higher drought affectedness and weaker instrumental social norms. These findings support the concept that behaviour is influenced by social norms and constraining variables (Ajzen, 1985, 1991).

From a policy perspective, landholders who perceive they experience less drought affectedness may be motivated by injunctive social norms to continue maintaining stock exclusion behaviours. Landholders who perceive their businesses are more affected by drought may require additional support to continue excluding stock from riverbanks. In Victoria, drought relief funding, including funding for stock management, is allocated based on climate data about the severity of drought conditions. This funding could be used to subsidize the purchase of stock feed, and thus, encourage landholders to continue excluding stock from riverbanks during drought conditions when riverine ecosystems are highly vulnerable to stock grazing (Jansen \& Robertson, 2001).

However, perceptions of drought affectedness are related to both actual drought severity, and the amount of overall income that landholders obtain from farm activities. Between 1994 
and 2010 CMA C experienced greater drought severity than either CMA A or CMA B. However, landholders in CMA A and CMA B reported higher drought affectedness. On average, landholders in CMA C obtain 20\% less income from farm activities than landholders in CMA A, and $15 \%$ less income than landholders in CMA B. While the difference is not statistically significant, these observations are consistent with previous findings that on average landholders in CMA C obtain a high proportion of income from off-farm activities, compared to other regions in Victoria (e.g., Wilson et al., 2003). Thus, to be effective, agencies that offer drought relief funding should consider the dynamics of regional employment. Landholders who receive a larger proportion of their income from farm activities perceive themselves as more drought affected, and are more likely to continue grazing the fenced frontage, compared to landholders who receive a smaller portion of their income from farm activities. During drought events government agencies, could encourage the maintenance of stock exclusion behaviours by subsidizing stock feed for landholders who rely heavily on farm businesses for income.

Taken together, our findings suggest that landholder behaviour is related to instrumental injunctive social norms about the responsibility of farmers for environmental management in drought conditions, as well as perceived drought affectedness. Perceived drought affectedness is related to both actual drought severity and the amount of income that landholders obtain from farm activities.

\subsection{Descriptive social norms}

Responses to the seven descriptive norm items were unexpected. We anticipated that landholders would estimate how others behave and that their responses would be consistent with their own behaviour. For example, landholders who graze should report that others like them graze more frequently than landholders who do not graze (Cialdini, 2007). Responses to descriptive norm items suggest that most landholders were unable to estimate how others like them behave for three reasons. Firstly, responses suggest that our participants believe that performing environmental behaviour (whether or not that behaviour is successfully maintained) distinguishes themselves from most other landholders. Behaviour can be motivated by both the desire for social acceptance and by the need to confirm self-identity (Conner \& Armitage, 1998). Thus, landholders who participate in stock exclusion projects may do so to reinforce their own selfidentity as environmental stewards, rather than to fulfil social expectations.

Secondly, responses indicate that landholders do not have enough knowledge about how others behave to form descriptive norms. Landholder properties are often boarded by farms and farmers that are not 'like them'; a cattle farmer may have neighbours that farm fruit trees. Descriptive norms form when people have information about how others behave (Lapinski \& Rimal, 2005). Geographic and social isolation from other farmers involved in similar environmental behaviours may limit the amount of knowledge landholders have about how other farmers involved in stock exclusion projects actually behave.

Thirdly, responses indicated that landholders believe the behaviour of others like them is highly contextual, and varies between individuals. Our participants suggested that landholders may behave differently in times of good water availability, compared to times of drought, 
672

673

674

675

676

677

678

679

680

681

particularly if drought conditions result in shortages of stock feed produced on farm properties. Thus, landholders do not appear to hold salient descriptive norms about stock exclusion projects.

These results suggest two avenues for environmental policy and improving the outcomes of voluntary instruments in rural communities. Firstly, educating landholders about the prevalence and nature of environmental behaviour in farming communities may promote a sense of group membership and activate accurate descriptive social norms (Cialdini, 2003). Secondly, appealing to self-identity, such as designing interventions directed stewardship and the unique contribution of landholders in remote areas, may reach landholders who do not perceive themselves to be a member of a group of environmentally-minded agriculturalists.

\section{Conclusion}

To improve the condition of river ecosystems stock exclusion behaviours must be maintained indefinitely (Moore \& Rutherfurd, 2017). In the absence of further financial incentives, or the enforcement of non-compliance, the maintenance of these projects rests on the motivation of individual landholders. An underlying assumption of using voluntary instruments is that landholders are motivated by non-monetary incentives, such as pro-environmental social norms (Danne, 2003). While social norms influence the adoption of agricultural environmental behaviour, such as stock exclusion behaviour, over time constraints related to drought conditions may weaken the influence of social norms on the continued maintenance of stock exclusion. This study examined the relationship between social norms, drought, and the maintenance of stock exclusion behaviour.

Our results support behavioural theory about the importance of social norms, and suggest that the distinction between symbolic and instrumental beliefs is relevant for understanding the maintenance of agricultural environmental behaviour in rural communities. We found that grazing behaviour is explained by both instrumental injunctive social norms about grazing, and perceived drought affectedness. Perceived drought affectedness is related to both actual drought severity, and the amount of income that landholders obtain from farm activities. Interestingly, landholders do not appear to hold salient descriptive norms about stock exclusion.

Overall, these findings suggest that landholders who perceive themselves to be more drought affected hold weaker social norms about stock exclusion, and are more likely to continue grazing stock on riverbanks. In the context of future climate change, voluntary agreements are likely to be effective for ensuring stock exclusion behaviour is maintained for landholders who obtain income from multiple sources, and, thus, are less dependent on farm productivity.

We make three observations that are relevant for future environmental policy, and research about understanding landholder behaviour:

- Education could be used to promote descriptive social norms about maintenance. Nearly half the landholders involved in this study continue to maintain stock exclusion. Information about what others 'actually' do could activate descriptive social norms (Cialdini, 2007) and encourage landholders to maintain stock exclusion behaviours;

- Drought relief packages already include funding for stock management. This could be targeted towards landholders involved in stock exclusion projects. Subsidizing the cost of 
additional feed could encourage landholders to exclude their stock from riverbanks during drought events, when riverbank vegetation is most vulnerable (Jansen \& Robertson, 2001);

- The distinction between injunctive and descriptive social norms, and symbolic and instrumental social norms have important implications for understanding landholder behaviour and designing interventions to promote environmental projects in rural areas. Rural research often includes very general measures of social factors, rather than specific cognitive social constructs. These nuances offer an avenue for future research, and the design of interventions.

Understanding the factors that influence landholders’ perceptions of drought affectedness is essential for designing policies to remove barriers to practice and encourage the voluntary maintenance of stock exclusion behaviours. Voluntary agreements that offer financial incentives for landholders to exclude stock from waterways have been effective for promoting the adoption of stock exclusion behaviours in Victoria. The next challenge is to ensure those behaviours are maintained indefinitely. This will involve a more nuanced understanding of the relationship between social norms and environmental behaviour in rural communities, and targeting drought relief packages to remove barriers to the continued maintenance of stock exclusion.

\section{References}

Aarons, S. R., Melland, A. R., \& Dorling, L. (2013). Dairy farm impacts of fencing riparian land: Pasture production and farm productivity. Journal of Environmental Management, 130, 255-266.

Ajzen, I. (1985). From intentions to actions: A theory of planned behaviour Action control (pp. 11-39): Springer.

Ajzen, I. (1991). The theory of planned behaviour. Organizational behaviour and human decision processes, 50(2), 179-211.

Ajzen, I. (2017). Sample TPB Questionnaire. Retrieved from http://people.umass.edu/aizen/tpb.html

Armitage, C. J., \& Conner, M. (2001). Efficacy of the theory of planned behaviour: A meta-analytic review. British Journal of Social Psychology, 40(4), 471-499.

Biel, A., \& Thøgersen, J. (2007). Activation of social norms in social dilemmas: A review of the evidence and reflections on the implications for environmental behaviour. Journal of Economic Psychology, 28(1), 93-112. doi:http://dx.doi.org/10.1016/j.joep.2006.03.003

Brooks, S. S., \& Lake, P. S. (2007). River restoration in Victoria, Australia: change is in the wind, and none too soon. Restoration Ecology, 15(3), 584-591.

Burton, R. J. (2004). Reconceptualising the 'behavioural approach'in agricultural studies: a sociopsychological perspective. Journal of Rural Studies, 20(3), 359-371.

Cary, J. (1993). The nature of symbolic beliefs and environmental behaviour in a rural setting. Environment and Behaviour, 25(4), 555-576.

Castro, F. G., Kellison, J. G., Boyd, S. J., \& Kopak, A. (2010). A methodology for conducting integrative mixed methods research and data analyses. Journal of mixed methods research, 4(4), 342-360.

Choi, B. C., \& Pak, A. W. (2005). Peer Reviewed: A Catalog of Biases in Questionnaires. Preventing Chronic Disease, 2(1).

Cialdini, R. B. (2003). Crafting normative messages to protect the environment. Current directions in psychological science, 12(4), 105-109.

Cialdini, R. B. (2007). Descriptive social norms as underappreciated sources of social control. Psychometrika, 72(2), 263. 
Cialdini, R. B., Reno, R. R., \& Kallgren, C. A. (1990). A focus theory of normative conduct: Recycling the concept of norms to reduce littering in public places. Journal of personality and social psychology, 58(6), 1015.

Conner, M., \& Armitage, C. J. (1998). Extending the theory of planned behaviour: A review and avenues for further research. Journal of Applied Social Psychology, 28(15), 1429-1464.

Crandall, C. S., Glor, J., \& Britt, T. W. (1997). AIDS-Related Stigmatization: Instrumental and Symbolic Attitudes. Journal of Applied Social Psychology, 27(2), 95-123

Curtis, A., McDonald, S., Mendham, E., \& Sample, R. (2008). Understanding the social drivers for natural resource management in the Wimmera region. Institute for Land, Water and Society, Albury.

Danne, A. P. (2003). Voluntary Environmental Agreements in Australia: An Analysis of Statutory and Non-statutory Frameworks for the Implementation of Voluntary Environmental Agreements in Australia. Environmental and Planning Law Journal, 20(4), 287-318.

Department of Sustainability and Environmnet. (2011). CMA-Landholder riparian management agreement guidelines. Victoria: The State of Victoria.

Fielding, K. S., Terry, D. J., Masser, B. M., \& Hogg, M. A. (2008). Integrating social identity theory and the theory of planned behaviour to explain decisions to engage in sustainable agricultural practices. British Journal of Social Psychology, 47(1), 23-48.

Fuj, E. T., Hennessy, M., \& Mak, J. (1985). An evaluation of the validity and reliability of survey response data on household electricity conservation. Evaluation Review, 9(1), 93-104.

Göckeritz, S., Schultz, P., Rendón, T., Cialdini, R. B., Goldstein, N. J., \& Griskevicius, V. (2010). Descriptive normative beliefs and conservation behaviour: The moderating roles of personal involvement and injunctive normative beliefs. European Journal of Social Psychology, 40(3), 514-523.

Goldstein, N. J., Cialdini, R. B., \& Griskevicius, V. (2008). A room with a viewpoint: Using social norms to motivate environmental conservation in hotels. Journal of consumer Research, 35(3), 472-482.

Greiner, R., \& Gregg, D. (2011). Farmers' intrinsic motivations, barriers to the adoption of conservation practices and effectiveness of policy instruments: Empirical evidence from northern Australia. Land Use Policy, 28(1), 257-265. doi:10.1016/j.landusepol.2010.06.006

Gunningham, N. (2003). Voluntary and negotiated agreements in agriculture: Towards a partnership approach to resource management. Australasian Journal of Natural Resources Law and Policy, 8(Part 1), 1-28.

Hirsh, J. B. (2010). Personality and environmental concern. Journal of Environmental Psychology, 30(2), 245-248.

Horridge, M., Madden, J., \& Wittwer, G. (2005). The impact of the 2002-2003 drought on Australia. Journal of Policy Modeling, 27(3), 285-308.

Jansen, A., \& Robertson, A. I. (2001). Riparian bird communities in relation to land management practices in floodplain woodlands of south-eastern Australia. Biological Conservation, 100(2), 173-185.

Jansen, H. (2010). The logic of qualitative survey research and its position in the field of social research methods. Paper presented at the Forum Qualitative Sozialforschung/Forum: Qualitative Social Research.

Jones, D. A., Wang, W., \& Fawcett, R. (2009). High-quality spatial climate data-sets for Australia. Australian Meteorological and Oceanographic Journal, 58(4), 233-248.

Kebede, Y. (1992). Risk Taking Behaviour and New Technologies: The Case of Producers in the Central Highlands of Ethiopia. Quarterly Journal of International Agriculture, 31, 269-269.

Kondolf, G. M., Anderson, S., Lave, R., Pagano, L., Merenlender, A., \& Bernhardt, E. (2007). Two decades of river restoration in California: What can we learn? Restoration Ecology, 15(3), 516523.

Lapinski, M. K., \& Rimal, R. N. (2005). An explication of social norms. Communication theory, 15(2), 127-147. 
Lievens, F. (2007). Employer branding in the Belgian Army: The importance of instrumental and symbolic beliefs for potential applicants, actual applicants, and military employees. Human Resource Management, 46(1), 51-69.

Minato, W., Curtis, A., \& Allan, C. (2010). Social norms and natural resource management in a changing rural community. Journal of Environmental Policy \& Planning, 12(4), 381-403.

Moore, H. E., \& Boldero, J. M. (2017). Designing interventions that last: A classification of environmental behaviours in relation to the activities, costs, and effort involved for adoption and maintenance. Frontiers in Psychology: Environmental Psychology, 8(1874). doi:https://doi.org/10.3389/fpsyg.2017.01874

Moore, H. E., \& Rutherfurd, I. D. (2017). Lack of maintenance is a major challenge for stream restoration projects. River Restoration and Applications, 33, 1387-1399. doi:https://doiorg.ezp.lib.unimelb.edu.au/10.1002/rra.3188.

Mpelasoka, F., Hennessy, K., Jones, R., \& Bates, B. (2008). Comparison of suitable drought indices for climate change impacts assessment over Australia towards resource management. International Journal of Climatology, 28(10), 1283-1292.

Nelson, R., Kokic, P., Elliston, L., \& King, J.-A. (2005). Structural adjustment: a vulnerability index for Australian broadacre agriculture. Australian Commodities: Forecasts and Issues, 12(1), 171.

Qasem, N., Ali, M., Gul, A., \& Bilal, S. (2014). Effect of Items Direction (Positive or Negative) on the Factorial Construction and Criterion Related Validity in Likert Scale. Khazar Journal of Humanities and Social Sciences, 17(3), 77-84.

Rivis, A., \& Sheeran, P. (2003). Descriptive norms as an additional predictor in the theory of planned behaviour: A meta-analysis. Current Psychology, 22(3), 218-233.

Van Sonderen, E., Sanderman, R., \& Coyne, J. C. (2013). Ineffectiveness of reverse wording of questionnaire items: Let's learn from cows in the rain. PloS one, 8(7), e68967.

Solís Salazar, M. (2015). The dilemma of combining positive and negative items in scales. Psicothema, 27(2), 192-199.

Steffen, W. (2015). Thirsty Country: Climate Change and Drought in Australia. Retrieved from CLIMATECOUNCIL.ORG.AU: http://www.climatecouncil.org.au/uploads/37d4a0d2a372656332d75d0163d9e8b8.pdf

Victoria State Government. (2017). Drought Response Package. Retrieved from agriculture.vic.gov/agriculture/farm-management/drought/drought-response-package-overview

Wauters, E., Bielders, C., Poesen, J., Govers, G., \& Mathijs, E. (2010). Adoption of soil conservation practices in Belgium: an examination of the theory of planned behaviour in the agrienvironmental domain. Land Use Policy, 27(1), 86-94.

Wilson, A., Jansen, A., Curtis, A., \& Robertson, A. (2003). Understanding landholder management of riparian zones in the Goulburn Broken Catchment. Retrieved from NSW: 


\section{Highlights}

The main highlights of the research are as follows:

- Whether landholders continue to exclude stock from waterways over the long-term is influenced by social norms and perceived drought affectedness;

- Instrumental social norms about drought conditions influence behaviour, while symbolic social norms about ideal conditions (good water availability and high farm productivity) do not;

- Perceived drought affectedness is explained by actual drought severity and the amount of income landholders obtain from farm activities together;

- Landholders do not appear to hold salient descriptive norms about how others like them behave. 
Table 1

Hypotheses

\begin{tabular}{|c|l|}
\hline \multicolumn{2}{|c|}{ Hypotheses about stock exclusion \& injunctive social norms* } \\
\hline $\mathbf{1}$ & $\begin{array}{l}\text { No difference between those landholders that graze and those that do not graze, for the item about } \\
\text { excluding stock in years of good water availability. }\end{array}$ \\
\hline $\mathbf{2}$ & $\begin{array}{l}\text { No difference between those landholders that graze and those that do not graze, for the item about } \\
\text { excluding stock in years of high farm productivity. }\end{array}$ \\
\hline $\mathbf{3}$ & $\begin{array}{l}\text { Landholders who graze the riverbank would report weaker injunctive norms about } \text { excluding stock in years } \\
\text { of drought. }\end{array}$ \\
\hline $\mathbf{4}$ & $\begin{array}{l}\text { Landholders who graze the riverbank would report weaker injunctive norms about } \text { excluding stock in years } \\
\text { of low farm productivity. }\end{array}$ \\
\hline $\mathbf{5}$ & $\begin{array}{l}\text { The injunctive social norm about } \text { excluding stock in drought conditions, and perceived drought affectedness } \\
\text { would predict greater variance in whether or not landholders continue to graze the riverbank than the } \\
\text { normative belief alone. }\end{array}$ \\
\hline $\mathbf{6}$ & $\begin{array}{l}\text { Landhotheses about stock exclusion, drought \& income } \\
\text { exclude stock from the riverbank. }\end{array}$ \\
\hline $\mathbf{7}$ & \begin{tabular}{l} 
There will be a positive relationship between actual drought severity and perceived drought affectedness. \\
\hline $\mathbf{8}$
\end{tabular} $\begin{array}{l}\text { There will be a positive relationship between the percentage of overall income obtained from farm } \\
\text { activities and perceived drought affectedness }\end{array}$ \\
\hline $\mathbf{9}$ & \begin{tabular}{l} 
Landholders in CMA C would report higher drought affectedness than landholders in CMA A and CMA B. \\
\hline $\mathbf{1 0}$
\end{tabular} $\begin{array}{l}\text { Drought severity and the percentage of overall income obtained from farm activities would predict greater } \\
\text { variance in perceived drought affectedness than either variable individually. }\end{array}$ \\
\hline
\end{tabular}

*Hypothesis 1 and 2 related to symbolic injunctive social norms. Hypothesis 3 and 4 relate to instrumental injunctive social norms. 
Table 2

Symbolic and instrumental injunctive norm survey items

\begin{tabular}{|c|l|}
\hline \multicolumn{1}{|c|}{ Type } & \multicolumn{1}{c|}{ Item } \\
\hline Symbolic & $\begin{array}{l}\text { Landholders should be prepared to exclude stock from the fenced frontage only in } \\
\text { years of good water availability. }\end{array}$ \\
\hline Symbolic & $\begin{array}{l}\text { Landholders should be prepared to exclude stock from the fenced frontage only in } \\
\text { years of high farm productivity. }\end{array}$ \\
\hline Instrumental & $\begin{array}{l}\text { Landholders should be prepared to exclude stock from the fenced frontage even in } \\
\text { years of drought. }\end{array}$ \\
\hline Instrumental & $\begin{array}{l}\text { Landholders should be prepared to exclude stock from the fenced frontage even in } \\
\text { years of low farm productivity. }\end{array}$ \\
\hline
\end{tabular}


Table 3

Correlations between injunctive norms.

\begin{tabular}{lccccccc}
\hline & $\mathrm{N}$ & Mean & SD & 1 & 2 & 3 & 4 \\
\hline 1.Good water availability & 92 & 3.68 & 2.29 & - & .09 & $.82^{* *}$ & .16 \\
2.Drought conditions & 91 & 4.36 & 2.33 & - & .08 & $.72 * *$ \\
3.High farm prod & 91 & 3.73 & 2.31 & & - & .20 \\
4.Low farm prod & 91 & 4.58 & 2.25 & & & - \\
$* * p<.01$ & & & & & & &
\end{tabular}


Table 4

Correlations between perceived drought affectedness, and income.

\begin{tabular}{lccccc}
\hline & $\mathrm{N}$ & Mean & $\mathrm{SD}$ & 1 & 2 \\
\hline 1.Drought affected & 90 & 5.12 & 2.071 & - & $.45^{* *}$ \\
2.Farm income \% & 87 & 50.58 & 41.406 & & - \\
& & & & & \\
\hline$* *<<.01$ & & & &
\end{tabular}




\section{Table 5}

Results of ANOVA for the difference between CMA A, CMA B, and CMA C for: the percentage income from on-farm activities, the drought severity ratio, and the coefficient of variance.

\begin{tabular}{lccccc}
\hline & DF & SS & MS & F & P \\
\hline \% income & 2 & 6439.97 & 3219.99 & 1.91 & .15 \\
\hline Drought severity ratio & 2 & .03 & .01 & 46.93 & .00 \\
\hline $\begin{array}{l}\text { Coefficient of } \\
\text { variance }\end{array}$ & 2 & .04 & .02 & 31.07 & .00 \\
$\begin{array}{l}* \text { DF = degrees freedom, SS = sum of squares, MS = mean square, F = F-statistic, } \\
\mathrm{P}=\text { P-value }\end{array}$
\end{tabular}


Table 6

T-test results for Hypotheses 1, 2, 3, 4 and 6.

\begin{tabular}{clllllll}
\hline Hypothesis & & $\mathrm{N}$ & Mean & SD & $\mathrm{t}$-cal & $\mathrm{df}$ & $\mathrm{p}$ \\
\hline \multirow{2}{*}{1} & Graze & 51 & 3.53 & 2.23 & -.711 & 89 & .48 \\
& Exclude & 40 & 3.88 & 2.39 & & & \\
\hline \multirow{2}{*}{2} & Graze & 51 & 3.35 & 2.22 & -1.76 & 89 & .08 \\
& Exclude & 40 & 4.20 & 2.37 & & & \\
\hline \multirow{2}{*}{3} & Graze & 51 & 3.73 & 2.32 & -3.09 & 89 & .00 \\
& Exclude & 40 & 5.18 & 2.11 & & & \\
\hline \multirow{2}{*}{4} & Graze & 51 & 4.02 & 2.41 & -2.89 & 89 & .00 \\
& Exclude & 40 & 5.30 & 1.81 & & & \\
\hline \multirow{2}{*}{6} & Graze & 52 & 5.54 & 1.90 & 2.28 & 88 & .03 \\
& Exclude & 38 & 4.55 & 2.18 & & & \\
\hline
\end{tabular}




\section{Table 7}

Results of the stepwise multiple regression for whether or not landholders graze: the instrumental injunctive norm about drought conditions and perceived drought affectedness.

\begin{tabular}{|c|c|c|c|c|c|c|}
\hline \multirow[b]{2}{*}{ Variable } & \multicolumn{3}{|c|}{ Model 1} & \multicolumn{3}{|c|}{ Model 2} \\
\hline & B & SE & $\beta$ & B & SE & $\beta$ \\
\hline Instrumental injunctive norm & .07 & .02 & .32 & .07 & .02 & .32 \\
\hline Drought affectedness & & & & -.05 & .02 & -.22 \\
\hline
\end{tabular}


Table 8

Results of the stepwise multiple regression for perceived drought affectedness: the percentage of income obtained from farming businesses and drought severity.

\begin{tabular}{lcccccc}
\hline & \multicolumn{3}{c}{ Model 1 } & & Model 2 \\
\hline Variable & B & SE & $\beta$ & B & SE & $\beta$ \\
\hline Percentage of income & .02 & .00 & .48 & .02 & .00 & .42 \\
Drought severity & & & & 29.87 & 11.89 & .26 \\
\hline
\end{tabular}




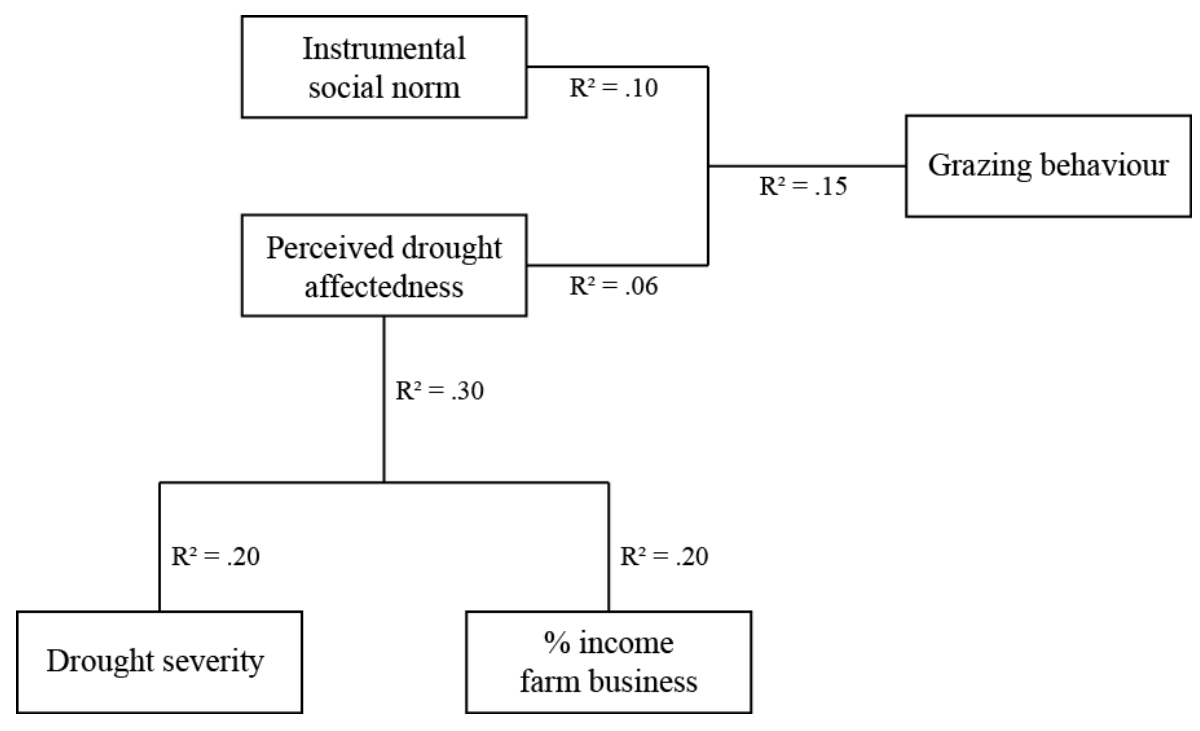

Fig. 1. Multiple regression model for: the variance of grazing behaviour explained by the instrumental social norm about drought and perceived drought affectedness; and the variance of perceived drought affectedness explained by drought severity and the percentage of overall income obtained from farm businesses. 